\title{
Dasar Pemikiran Pemilihan Energi Alternatif yang Ramah Lingkungan Dan Tahapan Penguasaan Teknologinya
}

\author{
Agus Rusyana Hoetman ${ }^{1 a)}$ \\ ${ }^{1}$ Balai Besar Teknologi Konversi Energi-BPPT \\ Serpong, Tangerang Selatan-Banten, Indonesia \\ a)arhoetman75@gmail.com (corresponding author)
}

\begin{abstract}
Abstrak
Indonesia mempunyai ragam sumber energi yang dapat dimanfaatkan untuk penyediaan energi masa depan. Ketersediaan sumber energi terdiri dari sumber energi fosil yang sudah mulai menipis, dan jenis energi baru dan terbarukan yang melimpah namun belum termanfaaatkan secara optimal. Proyeksi kebutuhan energi primer Indonesia selama 20 tahun kedepan dari tahun 2000 sampai 2020 meningkat, dimana akan dipenuhi oleh minyak bumi, gas bumi, batubara, hidro dan panas bumi. Guna memenuhi perkembangan tersebut perlu dirumuskan tahapan penguasaan dan pengembangan teknologi yang menghasilkan produk yang efisien dan ramah lingkungan. Tahapannya dengan membuat skenario perbaikan berdasarkan data eksisting baik dari ketersediaan sumber daya, teknologi dan pasar, terhadap kebutuhan dan strategi penyediaan energi masa depan. Selanjutnya analisis makro atas kondisi yang berjalan dan masa depan, termasuk kondisi kebijakan yang ada, dilanjutkan dg analisis mikro untuk menentukan langkah pemilihan teknologi, pembuatan standarisasi dan industrialisasi, kemudian diterbitkanya kebijakan baru yang berpihak kepada kekuatan nasional yang mengutamakan sumber dayanya.
\end{abstract}

Kata kunci: energi baru dan terbarukan, efisien, fosil, ramah lingkungan

\section{PENDAHULUAN.}

Energi merupakan darah dari sistem kehidupan bernegara, untk itu pembangunan dibidang energi harus diarahkan untuk mendorong se efisien mungkin untuk meningkatkan kesejahteraan rakyat. Saat ini pemakaian sumber daya energi didominasi dengan penggunaan sumber daya energi fosil, seperti bahan bakar minyak / minyak diesel, dan batubara, sedangkan pemakaian sumber daya energi baru dan terbarukan belum banyak dimanfaatkan. Hal ini mengakibatkan harga energi final menjadi mahal dan tidak baik terhadap lingkungan. Untuk menjamin serta mengoptimalkan penyediaan energi, pemerintah telah merancang kebijakan yang intinya menata penggunaan sumber energi, intensifikasi pencarian sumber baru dan melakukaan upaya konservasi serta menentukan arah penguasaan teknologi, untuk menjamin ketersediaaan energi dan menjaga lingkungan hidup.

Ketersediaan sumber daya energi fosil dan energi baru dan terbarukan diharapkan dapat memenuhi kebutuhan energi nasional yang terus berkembang sesuai dengan perkembangan industri, pertambahan penduduk dan gaya hidup masyarakat. Dikarenakan terbatasnya sumber energi fosil, beserta besarnya dampak lingkungan yang di diakibatkanya, maka pemanfaatan energi baru dan terbarukan diperlukan untuk mengatasi hal tersebut.

\section{KONDISI ENERGI DI INDONESIA}

\section{Ketersediaan Sumber Daya Energi}

Ketersediaan sumber energi nasional terdiri dari sumber daya energi fosil, serta energi baru dan terbaru. Sumber energi fosil di Indonesia yang penting dan mempunyai peran strategis adalah: Minyak bumi; Gas bumi dan batu bara. Ketersediaan energi fosil yang terbanyak dalam perbandingannya dengan cadangan dunia adalah Gas bumi, sebesar $2 \%$ dari cadangan dunia (137.793,6 BSCF), kemudian minyak bumi dengan cadangan $1 \%$ dari cadangan dunia $(9.091,9$ juta barel), serta cadangan batubara sebesar 36 milyard ton, cadangan ini bila dibandingkan dengan cadangan dunia hanya sebesar $0,34 \%$ dari cadangan dunia, hanya kualitas nya diperkirakan $60 \%$ berupa batubara muda. Data lengkap ditunjukkan pada Tabel 1.

Tabel 1. Potensi Energi Fosil [1]

\begin{tabular}{|c|c|c|c|c|c|}
\hline & POTENSI & $\begin{array}{c}\text { CADANG } \\
\text { AN }\end{array}$ & $\begin{array}{c}\text { DIPRODU } \\
\text { KSI }\end{array}$ & $\begin{array}{l}\text { Perbandin } \\
\text { gan dgn. } \\
\text { Cadangan }\end{array}$ & Catatan \\
\hline $\begin{array}{l}\text { Minyak } \\
\text { Bumi }\end{array}$ & $\begin{array}{c}56,6 \\
\text { Milyar } \\
\text { barel }^{*}\end{array}$ & $\begin{array}{c}8,4 \\
\text { Milyar } \\
\text { barel }\end{array}$ & $\begin{array}{c}348 \text { juta } \\
\text { barel }\end{array}$ & $1 \%$ & \\
\hline $\begin{array}{l}\text { Gas } \\
\text { Bumi }\end{array}$ & $\begin{array}{l}334,5 \\
\text { TSCF }\end{array}$ & $\begin{array}{c}165 \\
\text { TSCF }\end{array}$ & $\begin{array}{c}2,79 \\
\text { TSCF }\end{array}$ & $2 \%$ & \\
\hline $\begin{array}{l}\text { Batu } \\
\text { Bara }\end{array}$ & $\begin{array}{c}90,5 \text { milyar } \\
\text { ton }\end{array}$ & $\begin{array}{c}18,7 \\
\text { milyar ton }\end{array}$ & $\begin{array}{l}201 \text { juta } \\
\text { ton }\end{array}$ & $0,34 \%$ & $\begin{array}{c}60 \% \text { low } \\
\text { rank } \\
\text { (lignitik) } \\
5.000 \\
\mathrm{kcal} / \mathrm{kg}\end{array}$ \\
\hline
\end{tabular}


Energi Baru adalah jenis energi hasil pengembangan dengan teknologi baru, Contohnya Batubara Tercairkan (Liqiufied Coal), Gas Metana Batubara (Coal Bed Methane), Batubara Tergaskan (Gasified Coal), Nuklir, dan Hidrogen. Sedangkan contoh dari Energi Terbarukan adalah: Panas Bumi, Aliran dan Terjunan Air (Hidro), Bioenergi, Sinar Matahari , Angin, Gerakan dan Perbedaan suhu Lapisan Laut Ketersedian energi terbarukan cukup beragam dengan potensi total sekitar 1204,07 $10^{6} \mathrm{MW}$, dengan kapasita terpasang baru 511,73 MW yaitu 4,25 $10^{-5}$ persen. Potensi yang paling banyak adalah energi surya mencapai 1203.75 $10^{6} \mathrm{MW}$ namun baru termanfaatkan $2.5710^{-7}$ persen, kapasitas terpasang tertinggi adalah mikro hydro, hal ini karena teknologinya sdh memasyarakat, dan berkembang dikalangan masyarakat. Data lengkap ditunjukkan pada tabel 2 .

Tabel 2. Potensi dan kapasitas terpasang EBT [1]

\begin{tabular}{|l|c|c|c|c|}
\hline Sumber Energi & \multicolumn{2}{|c|}{ Potensi } & $\begin{array}{c}\text { Kapasitas } \\
\text { Terpasang }\end{array}$ & $\begin{array}{c}\text { Persentase } \\
\text { Pemanfaatan }\end{array}$ \\
\hline & $1000 \times($ SBM & (MW) & (MW) & $(\%)$ \\
\hline Minyak Bumi & 105610,68 & 19658,00 & 309,50 & 1,57 \\
\hline Mikrohidro & 2464,59 & 458,75 & 20,85 & 4,54 \\
\hline Surya & $2155,60.10^{9}$ & $1203,75 \cdot 10^{6}$ & $0,88(3,09)$ & $7,31 \cdot 10^{8}\left(2,57 \cdot 10^{-7}\right)$ \\
\hline Angin & $16630,50.10^{3}$ & 9286,61 & 0,38 & $4.09 \cdot 10^{-3}$ \\
\hline Biomasa & 267585,54 & 49807,43 & 177,85 & 0,36 \\
\hline Biogas & 127,47 & 684,83 & 0,06 & $8,76 \cdot 10^{-3}$ \\
\hline Gambut & $16,88.10^{6}$ & - & - & - \\
\hline Panas Laut & 1289376,49 & 240000 & - & $4,23.10^{-5}\left(4,25.10^{-5}\right)$ \\
\hline Total & $2155,64.10^{9}$ & $1204,07.10^{6}$ & $509,52(511,73)$ & - \\
\hline
\end{tabular}

Kebutuhan Energi.

Proyeksi kebutuhan energi primer Indonesia tahun 1995 - 2020 ditunjukkan pada tabel 3.
Tabel 3. Proyeksi kebutuhan energy primer Indonesia tahun 1995-2020 (x 1000 SBM) [2]

\begin{tabular}{|r|r|r|r|r|l|}
\hline Minyak & Gas Bumi & Batubara & Hidro & \multicolumn{1}{c|}{$\begin{array}{c}\text { Panas } \\
\text { Bumi }\end{array}$} & \multicolumn{1}{l|}{ Total } \\
\hline 296.479 & 110.552 & 60.301 & 30.150 & 5.025 & 502.507 \\
\hline 374.897 & 152.736 & 124.966 & 34.713 & 6.943 & 694.255 \\
\hline 505.478 & 181.972 & 262.848 & 50.548 & 10.110 & 1.010 .956 \\
\hline 685.373 & 258.919 & 502.607 & 60.922 & 15.231 & 1.523 .052 \\
\hline 871.586 & 392.214 & 806.217 & 87.159 & 21.790 & 2.178 .966 \\
\hline 1.111 .242 & 634.995 & 1.301 .741 & 95.249 & 31.750 & 3.174 .977 \\
\hline
\end{tabular}

Proyeksi kebutuhan energi primer Indonesia selama 20 tahun kedepan dari th 2000 sampai 2020 meningkat sebesar 4,6 kali, dimana akan dipenuhi oleh minyak bumi yang akan naik 2.5 kali, gas bumi naik 4,2 kali, batubara naik 10,5 kali, hidro naik 2,7 kali, dan panas bumi naik 4,6 kali.

Guna memenuhi perkembangan tersebut perlu dirumuskan tahapan penguaasaan dan pengembangan teknologi yang menghasilkan produk yang efisien dan ramah lingkungan.

\section{Kontribusi Energi Primer}

Energi primer yang dimaksud terdiri dari energi Minyak bumi, gas bumi, batubara, hydro dan panas bumi. Sedangkan energi surya belum masuk dalam analisis. dari rentang waktu tahun 2000 hingga tahun 2020 diperkirakan minyak bumi berkontribusi paling banyak, yaitu $44 \%$, gas bumi $19 \%$, batubara $31 \%$, hydro sebesar $4,2 \%$ dan panas bumi $1 \%$, sedangkan target Dewan energi Nasional, energi baru terbarukan akan berkontribusi $25 \%$ di tahun 2025. Data kontribusi energi primer ditunjukkan pada tabel 4.

Tabel 4. Proyeksi kontribusi energi primer Indonesia [2]

\begin{tabular}{|c|c|c|c|c|c|c|}
\hline Tahun & $\begin{array}{c}\text { Minyak } \\
(\%)\end{array}$ & $\begin{array}{c}\text { Gas } \\
\text { Bumi } \\
(\%)\end{array}$ & $\begin{array}{c}\text { Batubar } \\
\text { a } \\
(\%)\end{array}$ & Hidro & $\begin{array}{c}\text { Panas } \\
\text { Bumi } \\
(\%)\end{array}$ & Total \\
\hline 1995 & 59 & 22 & 12 & 6 & 1 & 100 \\
\hline 2000 & 50 & 22 & 18 & 5 & 1 & 100 \\
\hline 2005 & 50 & 18 & 26 & 5 & 1 & 100 \\
\hline 2010 & 45 & 17 & 33 & 4 & 1 & 100 \\
\hline 2015 & 40 & 18 & 37 & 4 & 1 & 100 \\
\hline 2020 & 35 & 20 & 41 & 3 & 1 & 100 \\
\hline
\end{tabular}




\section{TUJUAN PEMBANGUNAN ENERGI (STRATEGI PEMANFAATAN ENERGI)}

Pembangunan energi bertujuan menyediakan sumber daya energi dan energi untuk masa depan. Secara rinci srategi pemanfaatan energi dalam rangka pembangunan energi, langkah-langkahnya adalah sebagai berikut:

1. Menjamin serta mengoptimalkan penyediaan energi dari berbagai sumber.

2. Mengoptimalkan sumber daya energi dengan tetap mendukung upaya mempertahankan fungsi lingkungan.

3. Mengoptimalkan alokasi energi dalam proses penciptaan nilai tambah

4. Mengoptimalkan alokasi energi dalam upaya upaya memperoleh devisa

Secara diagramatis alur pikir tahapan Pengkajian, Pengembangan dan Penerapan Teknologi Energi yang Efisien dan Ramah Lingkungan adalah seperti digambarkan pada Gambar 1. Strategi tersebut dilakukan dalam rangka menyusun Tahapan pengkajian, pengembangan dan penerapan teknologi yang efisien.

Tahap pertama menginventarisasi sumber daya energi, teknologi dan pasar yang ada pada saat itu, kemudian melakukan analisis dan membuat scenario perbaikan berdasarkan kondisi eksisting, terhadap kebutuhan dan strategi penyediaan energi masa depan. Tahapan selanjutnya melakukan analisis makro atas kondisi yang berjalan dan masa depan, termasuk kondisi kebijakan yang ada, dilanjutkan dengan melakukan mikro analisis untuk menentukan langkah-langkah pemilihan teknologi, sistem integrasi, sosialisasi serta pembuatan standarisasi dan industrialisasi yang kemudian diterbitkanya kebijakan baru yang berpihak kepada kekuatan nasional yang mengutamakan sumber daya lokal/nasional.

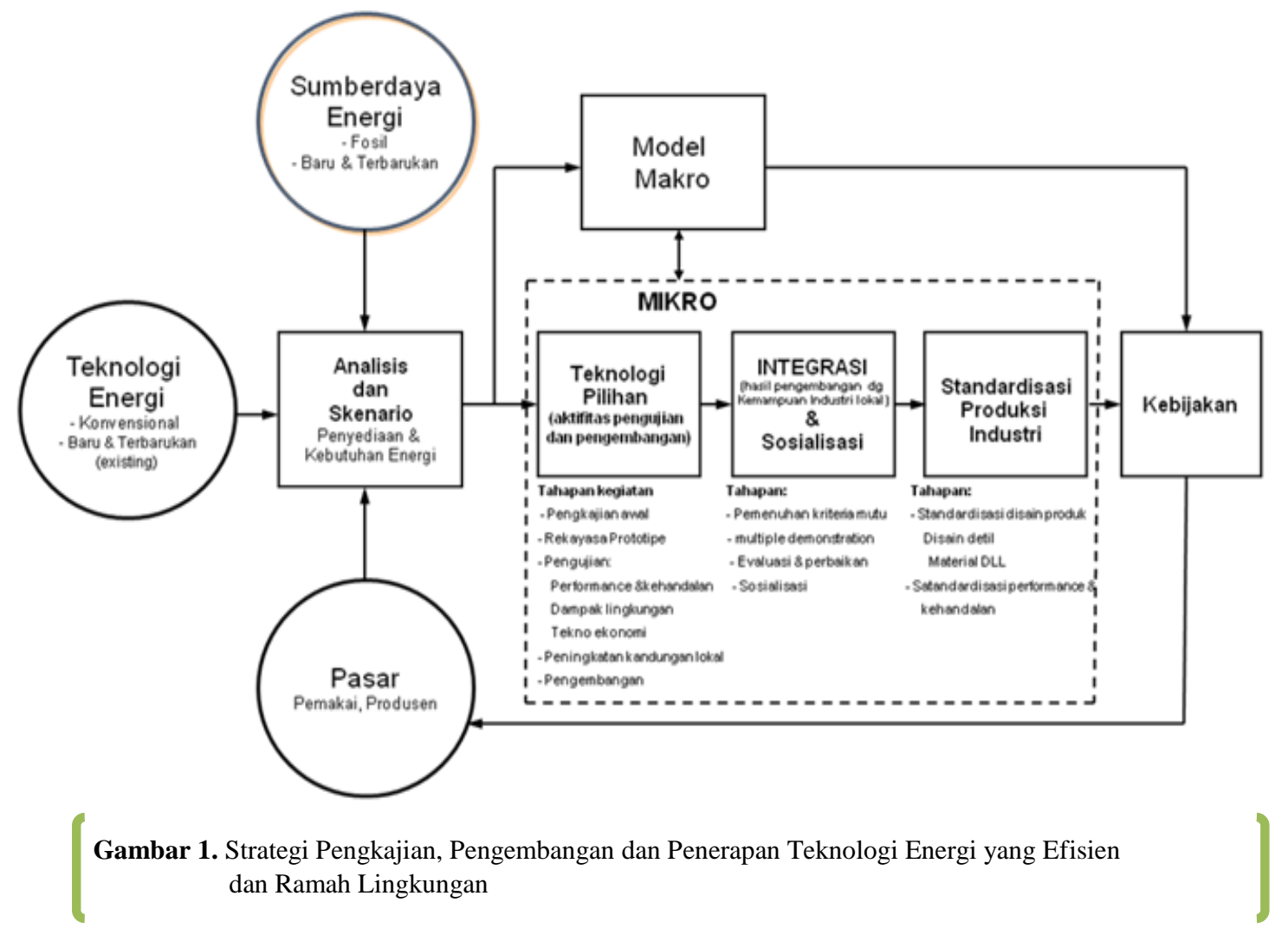


IV. TAHAPAN UNTUK MENENTUKAN ARAH PENERAPAN, PENGUASAAN, DAN PENGEMBANGAN TEKNOLOGI ENERGI YANG EFISIEN SERTA RAMAH LINGKUNGAN

\section{Analisis}

Sumber energi yang tersedia diantaranya jenis fosil, dimana cadangan potensial terbesar adalah batubara (Tabel 1). Pada jenis energi baru yang besar potensinya, serta ramah lingkungan adalah batubara tercairkan/tergaskan nuklir dan hydrogen. Sedangkan dari jenis energi terbarukan potensi panas bumi besar untuk energi kapasitas besar yang kontinu sedangkan untuk jenis pembangkitan kecil dan sedang potensi energi surya cukup melimpah. Perkiraan kebutuhan Energi primer berdasarkan proyeksi sampai dengan tahun 2020 (tabel 3) bahwa kebutuhan akan minyak masih dominan setelah batubara. Berdasarkan data ketersediaan sumber energi, dan kebutuhan/permintaan yang ada di Indonesia, dimana batubara dan energi matahari merupakan sumber yang melimpah dan relatif mudah teknologinya khususnya pada teknologi energi/pembangkit tenaga listrik umumnya pembangkit energi, telah tersedia dan berkembang secara cepat, baik itu yang konvensional maupun hasil inovasi baru. Selain itu tingkat dan arah perkembangan aplikasi teknologi untuk memanfaatkan dua jenis sumberdaya tersebut juga sudah relatif baik dan berwawasan lingkungan. Atas dasar itu diperlukan suatu strategi penguasaan dan pengembangan teknologi untuk mendapatkan suatu teknologi yang efisien dan ramah lingkungan yang dikuasai secara terintegrasi dan mandiri.

\section{Tahapan Penguasaan Teknologi Energi}

Setelah dilakukan analisis terhadap sumber daya energi yang tersedia, ketersediaan/perkembangan Teknologi Energi dan permintaan/kebutuhan yang didasarkan permintaan pasar dan kebijakan pemerintah, maka tahapan selanjutnya adalah perumusan tahapan/strategi penguasaan, pengembangan serta penerapan teknologi yang terintegrasi dan mandiri yakni melakukan pengkajian terhadap teknologi pilihan, dengan tahapan kegiatan:

$\begin{array}{rlr}\text { I. } & \text { Rekayasa rancang bangun prototype } \\ \text { II. } & \text { Pengujian unjuk kerja, kehandalan, dan } \\ & \text { dampak lingkungan } \\ \text { III. } & \text { Analisis tekno ekonomi } \\ \text { IV. } & \text { Peningkatan kandungan lokal } \\ \text { V. } & \text { Pengembangan peralatan } \\ \text { VI. } & \text { Integrasi hasil pengembangan dengan } \\ & \text { kemampuan industri lokal serta } \\ & \text { sosialisasi } \\ \text { VII. } & \text { Pemenuhan kriteria mutu } \\ \text { VIII. } & \text { Multiple demonstration } \\ \text { IX. } & \text { Evaluasi dan perbaikan } \\ \text { X. } & \text { Standarisasi produksi industri } \\ \text { XI. } & \text { Standardisasi disain produk } \\ \text { XII. } & \text { Pembuatan disain detil serta } \\ & \text { prosedurnya }\end{array}$

XIII. Pemilihan/penentuan material

XIV. Standardisasi performance dan kehandalan

Tahapan selanjutnya adalah sosialisasi pasar dan memberikan masukan untuk kebijakan pemerintah.

\section{KESIMPULAN}

Cadangan sumberdaya hidrokarbon (fosil) terbatas dibanding dengan cadangan dunia. Sumber cadangan yang potensial yang terbesar adalah batubara. Pangsa pemakaian minyak bumi dalam penyediaan energi nasional masih cukup besar, sementara peranan migas sebagai penghasil devisa diharapkan sekali. Sehingga diperlukan strategi penggunaan batubara sebagai energi alternatif yang ramah lingkungan atau sebagai energi baru. Kelompok energi baru yang perlu dipertimbangkan memenuhi syarat ke ekonomian dengan ramah lingkungan adalah nuklir, hydrogen dan jenis energi baru berdasar batubara, misal batubara tercairkan. Jenis energi terbarukan merupakan hal penting untuk di kuasai teknologinya, meskipun secara ekonomi belum bersaing. Jenis tersebut adalah energi surya, panas bumi, energi laut dan air, biomassa serta energi angin. Untuk itu arah pengembangan teknologinya perlu diperhatikan.

Perkembangan teknologi dalam pengelolaan batubara berkembang dengan pesat, baik untuk penggunaan batubara langsung untuk sumber energi (bahan bakar), maupun teknologi konversi dari batu bara menjadi bahan bakar lain (bahan bakar cair) yang semuanya mengarah ke teknologi yang ramah lingkungan, sehingga dari pertimbangan tersebut layak batubara diunggulkan sebagai energi alternatif, dengan pengolahan yang ramah lingkungan.

Energi baru dan terbarukan cadangannya cukup besar, potensial untuk dikembangkan, namun pada saat ini belum kompetitif dibanding dengan energi konvensional. Untuk kapasitas kecil sampai sedang energi surya adalah salah satu yang mempunyai potensi yang tinggi, sedangkan untuk kapasitas sedang dan besar panas bumi adalah berpotensi untuk dikembangkan,karena ramah lingkungan.

Perkembangan teknologi untuk memanfaatkan energi ini cukup baik dibanding dengan perkembangan teknologi untuk energi baru lainnya. Arah perkembangannya pada umumnya dikatagorikan sebagai teknologi yang ramah lingkungan. Selain itu penggunaan/pemanfaatan energi ini sering dikatagorikan sebagai suatu energi alternatif yang independen dan relatif mudah penerapan/penggunaannya, terutama untuk daerahdaerah diluar jangkauan distribusi PLN. Sehingga Pengembangan dan penerapan energi dan teknologi energi surya layak sebagai energi alternatif unggulan bersama-sama dengan batubara. Tahapan penguasaan/pengembangan serta penerapan teknologi dapat mengikuti alur tahapan yang dijelaskan pada bagian II dan secara spesifik ditunjukkan pada gambar 2 . 


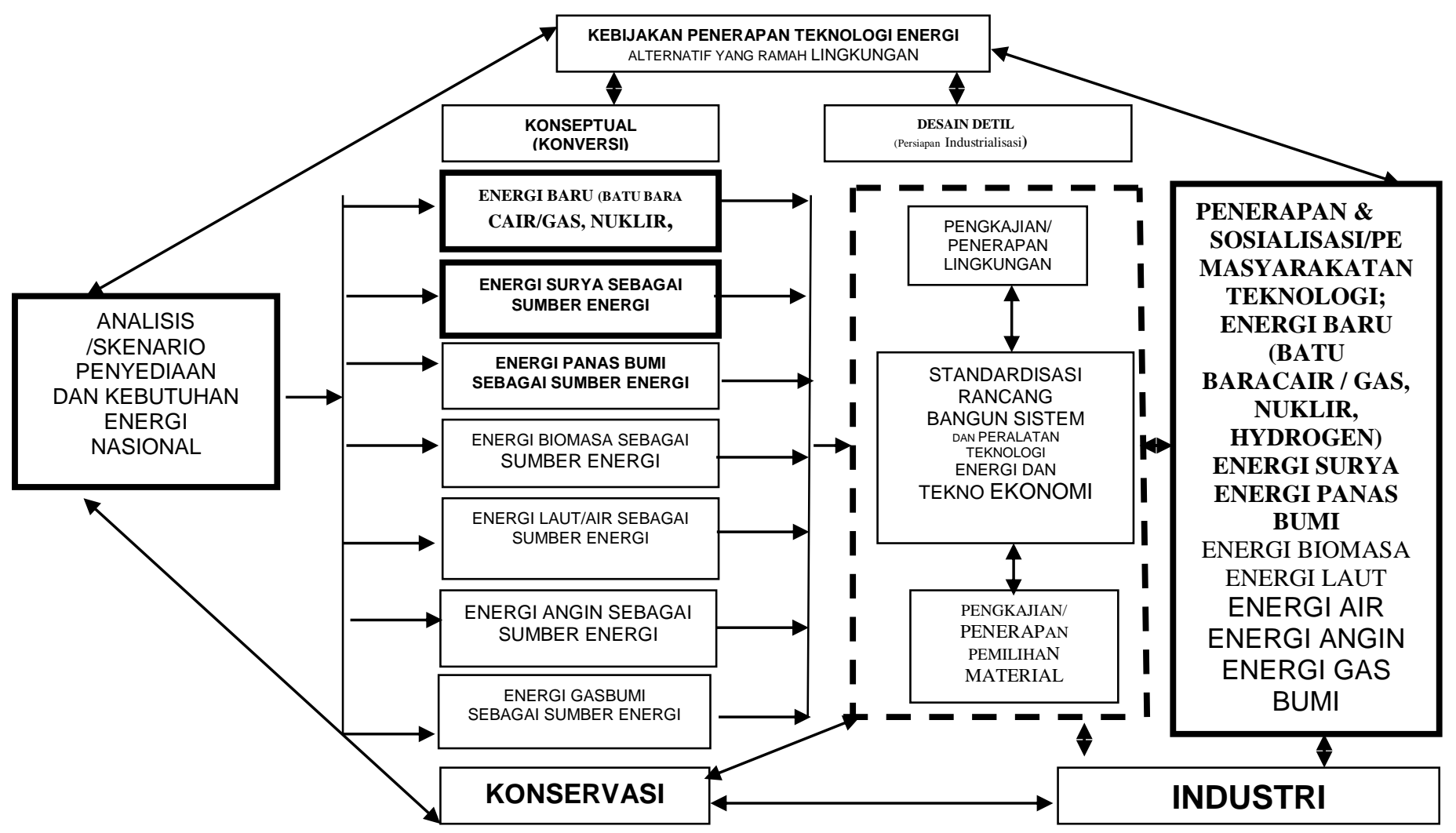

Gambar 2. Strategi Pengkajian, Pengembangan dan Penerapan Energi Alternatif yang Ramah Lingkungan

\section{REFERENSI}

[1] Menteri ESDM. SEMINAR Energi dalam Krisis.

Universitas Gadjah Mada, 28 Juni 08

[2] Zuhal. A, Energy \& Dev. In PJP II Workshop on Clean Energy for Environmental Protection \& Development. Jakarta 3- 4 Oktober 1992

[3] Kebijakan Energi Nasional. Dewan Energi Nasional Republik Indonesia (draft KEN). Jakarta, 2013.

[4] Hoetman, Agus Rusyana DR., Strategi pemenuhan kebutuhan energi untuk ketahanan nasional. Karya Tulis Ilmiah Perorangan, Kursus Pendidikan Lemhannas. 2009 